\title{
Influence of Temperature and Humidity on the Viability of Ophiognomonia clavigignenti-juglandacearum Conidia
}

\author{
M. J. Moore and M. E. Ostry, Northern Research Station, United States Department of Agriculture Forest Service, St. Paul, MN
}

\begin{abstract}
Moore, M. J., and Ostry, M. E. 2015. Influence of temperature and humidity on the viability of Ophiognomonia clavigignenti-juglandacearum conidia. Plant Dis. 99:1841-1846.

Butternut canker, caused by the fungus Ophiognomonia clavigignentijuglandacearum, primarily kills butternut (Juglans cinerea). Rain splash and local air currents are the primary means of conidia dispersal but that does not explain its long-distance spread and infection of isolated trees. Dispersal by insect or animal vectors or plant material likely necessitates the ability for conidia to tolerate drying for a period of time over variable temperature and humidity conditions. The objective of this study was to determine the influence of temperature and humidity on conidial germination and survival of air-dried conidia. Conidia collected from 1-month-old cultures germinated on water agar over a wide range of temperatures $\left(4\right.$ to $32^{\circ} \mathrm{C}$ ) and were viable after brief periods at $36^{\circ} \mathrm{C}$ when returned to a lower temperature. Viability of air-dried

conidia held on nylon membranes at various temperatures and humidities varied from less than a day at $28^{\circ} \mathrm{C}$ and $90 \%$ relative humidity (RH) to a mean of 15 days at $20^{\circ} \mathrm{C}$ and $80 \%$ RH. RH had the least effect on viability at $12^{\circ} \mathrm{C}$, with conidia remaining viable for 7 days at most humidity levels tested. Conidia held at $100 \% \mathrm{RH}$ began germinating on the membranes after 21 days. Conidia in a water suspension remained viable for 168 days at all temperatures tested. These results suggest that $O$. clavigignenti-juglandacearum conidia may remain viable on the surface of a vector or plant material and seed for over 2 weeks, given the proper conditions, or for much longer if in water or in an environment of saturated humidity. This potential may, in part, explain the frequent presence of the disease on isolated trees.
\end{abstract}

Butternut canker, caused by the fungus Ophiognomonia clavigignentijuglandacearum (2), is responsible for killing butternut (Juglans cinerea) throughout eastern North America. The disease was first reported in the United States in Wisconsin in 1967 (20) and is threatening the survival of the species throughout its native range (19). Butternut, although never commercially important for timber or nut production, is an ecologically important species in eastern hardwood forests. Scarcity of large trees resulting from tree mortality predominately caused by butternut canker has increased the value of the wood, highly prized for woodworking, and has reduced the availability of an important mast species for wildlife (18). Butternut bark extracts may have value for their high level of antibiotics (13), including some that inhibit human-pathogenic fungi (5).

Butternut is the primary species that is killed by the disease but cankers also have been found on black walnut (J. nigra) (16) and heartnut (J. ailantifolia var. cordiformis) (15). Artificial inoculations have produced cankers on Persian walnut (J. regia) in a plantation (14), and grafted plants of several commercially important Persian varieties in a greenhouse were highly susceptible (17). If the disease was to become established in California, where most of the U.S. commercial Persian walnut crop is grown, it could be devastating.

The fungus may be an exotic species, possibly brought to North America on Asian species of walnut seed or walnut planting stock (3). Recently, DNA evidence of $O$. clavigignenti-juglandacearum as an endophyte in twigs of Acer truncatum was reported from northern China (22). The fungus is able to infect leaves of butternut (2) and butternut hybrids (unpublished data).

Stromatal columns (hyphal pegs) produced by the fungus lift and split the outer bark, exposing the pycnidia that exude a sticky matrix of conidia during wet conditions. Transmission of the fungus has been attributed to dissemination of conidia by rain splash and aerosols up to

Corresponding author: M. Moore, E-mail: melaniemoore@fs.fed.us

Accepted for publication 16 June 2015.

http://dx.doi.org/10.1094/PDIS-09-14-0976-RE

This article is in the public domain and not copyrightable. It may be freely reprinted with customary crediting of the source. The American Phytopathological Society, 2015.
$40 \mathrm{~m}$ from the source (23). Conidia have been collected on spore traps over $45 \mathrm{~m}$ from a source only during periods of rainfall (11). The fungus can sporulate on dead trees for nearly 2 years (25). O. clavigignentijuglandacearum conidia in a simulated airborne state were viable for $8 \mathrm{~h}$ in the field and at least $32 \mathrm{~h}$ in an environmentally controlled chamber (24). Duration of conidia viability increased with reduced temperature and relative humidity $(\mathrm{RH})$. Conidia germinated after $48 \mathrm{~h}$ on either water agar or potato dextrose agar at temperatures from 8 to $32^{\circ} \mathrm{C}$, with the optimum being 24 to $28^{\circ} \mathrm{C}(26)$.

Dissemination of conidia in rain splash and air currents accounts for localized spread of the fungus, yet the disease is found nearly everywhere that butternut trees grow, even in isolated locations. The fungus is seedborne on butternut and black walnut (J. nigra) (9) but the large, heavy seed are only moved locally by squirrels and other rodents, and long-distance spread by seed would be dependent on human dispersal. Human movement of plant materials is also a potential pathway for the spread of $O$. clavigignenti-juglandacearum. Butternut selections that may have canker resistance are increasingly being propagated from seed and scion wood and placed in archive plantings. The potential of $O$. clavigignenti-juglandacearum survival on the surface of seed, seedlings, and scion wood during transport and storage is unknown. In addition, butternut is a riparian species. Water runoff potentially could move conidia to exposed buttress roots of butternut trees, infecting distant trees; however, the viability of conidia after extended periods in water is unknown.

Several potential insect vectors of $O$. clavigignenti-juglandacearum have been identified (10). In Vermont, 17 species of beetles were found to carry $O$. clavigignenti-juglandacearum conidia (8). Stewart and others (21) found that conidia remained viable on the bodies of three beetle species for up to 16 days.

Long-term viability of conidia of other fungi has been studied in regards to the practical application of biocontrol agents against pathogens and insects. For example, conidia of Beauveria bassiana, an entomopathogenic fungus, could be stored for the longest at cool temperatures and low humidity (4). Viability decreased with added light, increased humidity, and increased temperature. The conditions needed for maximum duration of $O$. clavigignenti-juglandacearum conidia viability have not been studied. This information is needed to more fully understand potential pathways of the pathogen and to prevent its inadvertent movement. The objectives of this study 
were to (i) determine the temperature range in which conidia of O. clavigignenti-juglandacearum can germinate over a longer period of time than previously studied or reported, (ii) determine the viability of $O$. clavigignenti-juglandacearum conidia after air drying and storage under several temperature and $\mathrm{RH}$ regimes, and (iii) determine the viability of $O$. clavigignenti-juglandacearum conidia after an extended time stored in water.

\section{Materials and Methods}

Fungal isolates and preparation of conidial suspensions. $O$. clavigignenti-juglandacearum isolates were obtained from cankers on branches of butternut trees in Minnesota and Wisconsin (Table 1). Outer bark was peeled from branches, and 5-mm chips of wood at the canker margin were excised. Samples were surface sterilized in $10 \%$ commercial bleach for $1 \mathrm{~min}$, then rinsed twice in sterile deionized water. Cultures were grown on $3 \%$ malt agar in the dark at $20^{\circ} \mathrm{C}$. Conidia were harvested from sporulating 1-monthold cultures by scraping with a sterile bent needle, and were placed in sterile deionized water. The suspension was vortexed, and allowed to sit for approximately $0.5 \mathrm{~h}$ to allow any hyphal fragments and agar to settle out. The conidial concentration was determined with a hemacytometer and diluted to 400 to 800 conidia/ $\mu$ l. Preliminary tests revealed that $O$. clavigignenti-juglandacearum conidial germination was inhibited at higher concentrations.

Temperature effects on germination of conidia. The temperature range chosen for the conidia germination study was in $4^{\circ} \mathrm{C}$ increments from 4 to $36^{\circ} \mathrm{C}$, temperatures typical of those experienced in the range of butternut during the growing season. Four isolates were chosen based on quantity of conidial production (Table 1).

The studies were performed using $1.5 \%$ water agar on sterile petri slides (Millipore Corp, Billerica, MA). For each test, a conidial suspension $(50 \mu \mathrm{l}$, with 400 to 800 spores/ $\mu \mathrm{l})$ of one of the four $O$. clavigignenti-juglandacearum isolates was placed on a slide and surface dried in a laminar flow hood for up to approximately $0.5 \mathrm{~h}$ to remove free moisture. They were then covered and incubated in the dark in controlled chambers at the designated temperatures. Two replicate slides per treatment per isolate were prepared. Germination of 200 random conidia was determined daily for 8 days at $\times 200$ using a light microscope until approximately $90 \%$ germination was obtained or to the point at which the quantity of hyphae of germinated conidia made it difficult to distinguish the remaining ungerminated conidia. A conidium was considered germinated when a germ tube was seen to be at least half of the spore length. The experiment was repeated once.

When it was clear that conidia did not germinate at $36^{\circ} \mathrm{C}$, an additional test was undertaken to determine whether that temperature was lethal or merely inhibitory. Four slides (one of each isolate) were incubated at $36^{\circ} \mathrm{C}$ for 1 to 4 days and then incubated at $20^{\circ} \mathrm{C}$. Viability was assessed as described above after 3 days.

Temperature and RH effects on viability of air-dried conidia. Glycerol solutions in a closed container control the RH of the air in that container in direct proportion to the concentration of the glycerol. Solutions of water and glycerol were made to correspond to 40, 80, 90, and $100 \%$ RH according to published protocols (6). For each $\mathrm{RH}, 100 \mathrm{ml}$ of solution was placed in the bottom of a square

Table 1. Ophiognomonia clavigignenti-juglandacearum isolates used in conidia viability studies

\begin{tabular}{llccc}
\hline Isolate & Location & $\begin{array}{c}\text { Year } \\
\text { isolated }\end{array}$ & $\begin{array}{c}\text { Temperature } \\
\text { study }\end{array}$ & $\begin{array}{c}\text { Viability after } \\
\text { drying and } \\
\text { water storage } \\
\text { studies }\end{array}$ \\
\hline 1343 & Whitewater, WI & 2002 & $\mathrm{X}$ & $\ldots$ \\
1352 & New Ulm, MN & 2005 & $\mathrm{X}$ & $\ldots$ \\
1363 & Rum River State & 2006 & $\mathrm{X}$ & $\ldots$ \\
& Forest, MN & & & $\ldots$ \\
1366 & La Crosse, WI & 2006 & $\mathrm{X}$ & $\ldots$ \\
1391 & Roseville, MN & 2011 & $\ldots$ & $\mathrm{X}$ \\
1394 & Afton, MN & 2011 & $\ldots$ & $\mathrm{X}$ \\
\hline
\end{tabular}

plastic food container (GladWare, 3 1/8 cup), and a 100-mm glass petri dish bottom was inverted over it to serve as a dry platform (Fig. 1). Containers were sealed with the clear cover and allowed to equilibrate in temperature chambers at 12,20 , and $28^{\circ} \mathrm{C}$. $\mathrm{RH}$ was measured with a small pen-sized hygrometer placed in the covered container, and glycerol solutions were adjusted if needed to $\pm 3 \%$ of the target humidity. RH of $100 \%$ was achieved by using deionized water only.

Approximately 20 nylon membrane filters $(0.2-\mu \mathrm{m}$ pore size; MSI, Honeoye Falls, NY) per isolate-treatment combination were sterilized by dipping in $70 \%$ ethanol and air dried in a sterile laminar flow hood. Conidia suspensions (50 $\mu$ l of 400 to 800 conidia/ $\mu l)$ of two separate isolates (Table 1) were each placed on a membrane and allowed to air dry in open plastic $100-\mathrm{mm}$ petri dishes in a laminar flow hood. When the membranes were dry the petri dishes were covered (but not sealed) and placed in the prepared humidity chambers (Fig. 1).

Daily for 7 days, then at 10 and 14 days, one filter from each treatment of each isolate was removed. They were inverted onto petri slides containing water agar and, after approximately $0.5 \mathrm{~h}$, the membranes were peeled off, leaving the conidia on the agar surface. Petri slides were covered and placed in a $20^{\circ} \mathrm{C}$ dark incubator, and the percentage of germination of 200 random conidia per plate was determined after 3 days at $\times 200$ with a light microscope. The experiment was repeated twice. Results are reported as combined mean of the two isolates and three experiments. After 14 days, membranes that had viable conidia within the previous two inspections were monitored periodically for viability up to 24 weeks, and the last day that viable conidia were present was recorded.

Viability of conidia after storage in water at various temperatures. At the same time as the above experiment, 1-ml aliquots of each conidial suspension were removed and placed in sterile $1.5-\mathrm{ml}$ microcentrifuge tubes. Tubes were placed in four temperatures $(4,12,20$, and $28^{\circ} \mathrm{C}$ ), with four tubes per isolate per treatment. Daily for 7 days and then at $10,14,21$, and 28 days, tubes were vortexed and $30-\mu l$ aliquots were removed and placed on water agar on petri slides. They were surface dried to remove free moisture in a laminar flow hood for approximately $0.5 \mathrm{~h}$, covered, and placed in a dark $20^{\circ} \mathrm{C}$ incubator. After 3 days, percent germination was determined. After 28 days, the conidial suspensions were monitored for viability every 4 weeks for 24 weeks. The experiment was repeated twice.

Statistical analysis. Temperature effects on conidial germination were first examined by individual growth curves, separated by isolate and experiment. The time required for the conidia to reach $80 \%$ germination was calculated via the scatterplot smoothed line function (Enterprise Guide 4.2; SAS Institute, Cary, NC). The smooth function produces a cubic spline that minimizes a linear combination of the sum of squares of the residuals of fit. To model the days to $80 \%$ germination, we used a generalized linear mixed model via PROC GLIMMIX (version 9.4; SAS Institute) with a pseudolikelihood estimation technique. Because of the long-right tail of the response variable, we used the $\gamma$ distribution and the log link function. Temperature and isolate were fixed effects in the model. Experiment was a random effect. We used the Kenward-Rogers denominator degrees of freedom adjustment method. Finally, to test for differences in the fixed effects, we used LSMEANS with the Tukey adjustment for multiple tests and a significance level of $P<0.05$.

To model the percent viability in the temperature and humidity test, we used a generalized linear mixed model via PROC GLIMMIX with a pseudolikelihood estimation technique. Because the response

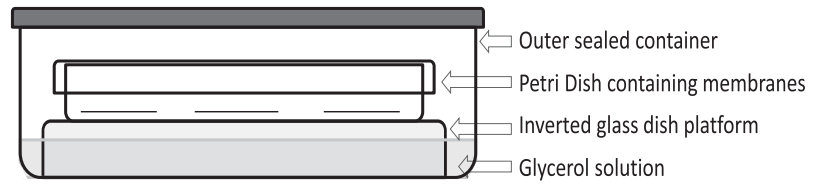

Fig. 1. Diagram of humidity chambers used to test viability of Ophiognomonia clavigignenti-juglandacearum conidia. 
variable was a percentage, we used the $\beta$ distribution and the logit link function. Because this distribution is bounded by 0 and 1 , we added or subtracted a small constant to keep $0 \mathrm{~s}$ and $1 \mathrm{~s}$ in the data set. Temperature or humidity and days were fixed effects in the model. Experiment was a random effect. We used the KenwardRogers denominator degrees of freedom adjustment method. Finally, to test for differences in the fixed effects, we used LSMEANS with the Tukey adjustment for multiple tests. Significance was tested at the $P<0.05$ level. Because of the low number of replications, the model would not converge when we tried to run the model with temperature, day, and humidity fixed effects. Therefore, we ran X (models) using the by statement to adjust for temperature or humidity.

Another data parameter, last day of survival, was also subjected to PROC GLIMMIX with the negative binomial distribution and the $\log$ link function. This tested the effect of temperature and humidity (fixed effects) on the number of days the conidia survived, and experiment was a random effect. To test for differences in the fixed effects, we used LSMEANS with the Tukey adjustment for multiple tests. Significance was tested at the $P<0.05$ level.

\section{Results}

Temperature effects on germination of conidia. Conidial germination occurred at a wide range of temperatures (Fig. 2A and B). Conidia at 20,24 , and $28^{\circ} \mathrm{C}$ reached $80 \%$ or greater germination in 3 days. Germination of conidia progressively slowed as temperature was lowered. Conidia held at $4{ }^{\circ} \mathrm{C}$ took a mean of 9.5 days to reach $80 \%$ germination (Table 2), although individual isolates ranged from 7.6 to 13 days. All treatments eventually reached $80 \%$ or greater germination except $32{ }^{\circ} \mathrm{C}$

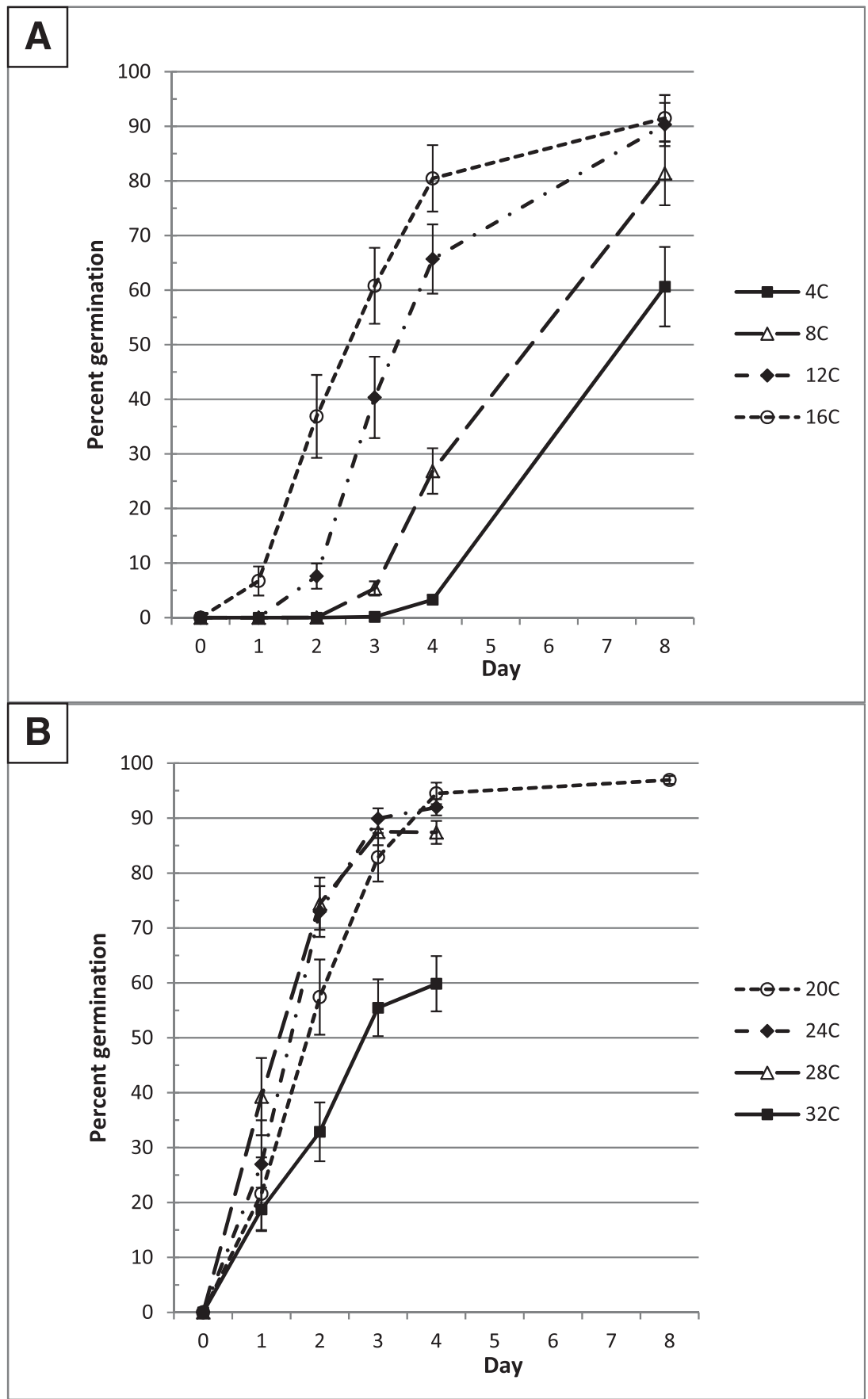

Fig. 2. Germination of Ophiognomonia clavigignenti-juglandacearum by temperature on water agar. Percentages are combined means of 200 conidia of each of four isolates, two slides of each isolate, and two experiments $(n=16) ; \mathbf{A}, 4$ to $16^{\circ} \mathrm{C}$ and $\mathbf{B}, 20$ to $32^{\circ} \mathrm{C}$. Bars represent standard errors. 
$(60 \%)$ and $36^{\circ} \mathrm{C}(0 \%)$. Temperature was a significant factor $(P<0.001)$ and mean separations had three groups (Table 2).

Isolate was a significant factor in the experiment $(P<0.001)$, with two isolates (1343 and 1366) germinating more slowly than the other two (1363 and 1352).

Table 2. Days needed to reach $80 \%$ germination of Ophiognomonia clavigignenti-juglandacearum by temperature on water $\operatorname{agar}^{\mathrm{Z}}$

\begin{tabular}{lccc}
\hline Temperature $\left({ }^{\circ} \mathbf{C}\right)$ & $\begin{array}{c}\text { Mean days to } \\
\mathbf{8 0 \%} \text { germination }\end{array}$ & SE & Range \\
\hline 4 & $9.5 \mathrm{a}$ & 0.80 & $7.6-13$ \\
8 & $7.8 \mathrm{a}$ & 0.85 & $4.6-13$ \\
12 & $5.1 \mathrm{~b}$ & 0.90 & $2.8-10.7$ \\
16 & $4.4 \mathrm{~b}$ & 1.27 & $1.8-13$ \\
20 & $2.7 \mathrm{c}$ & 0.31 & $1.4-4.2$ \\
24 & $2.2 \mathrm{c}$ & 0.27 & $0.9-3.0$ \\
28 & $2.4 \mathrm{c}$ & 0.50 & $0.7-4.6$ \\
\hline
\end{tabular}

${ }^{\mathrm{z}}$ Values are combined means of four isolates and two experiments $(n=8)$. Values with the same letter do not differ significantly according to Tukey's least significant difference test $(P<0.05)$. SE $=$ standard error.
Ungerminated conidia held at $36^{\circ} \mathrm{C}$ and then placed at $20^{\circ} \mathrm{C}$ were found to be viable, with germination decreasing with the number of days held at $36^{\circ} \mathrm{C}$ : after 1 day, $79 \% ; 2$ days, 26\%; 3 days, 3\%; and 4 days, less than $1 \%$.

Temperature and RH effects on viability of air-dried conidia. There was a clear reduction in viability (measured by percent germination) over time by all treatments (Fig. 3).When data were subjected to $\beta$ analysis, there was no significant difference in viability between isolates $(P=0.13)$; therefore, data from all isolates were combined. Significant $(P<0.0001)$ effects on conidia viability were found for day, temperature, and humidity. Although the interaction between temperature and humidity affected the data somewhat, in general, viability was the highest at $100 \%$, then $80 \% \mathrm{RH}$, and poorest at 40 and $90 \%$ RH. Similarly, viability was highest at $12^{\circ} \mathrm{C}$ and poorest at $28^{\circ} \mathrm{C}$.

When measured by days of survival, conidia held at the highest temperature lost viability more quickly than at lower temperatures $(P<0.0001)$ (Table 3). Conidia held at 28 and $20^{\circ} \mathrm{C}$ lost viability very quickly at 40 and $90 \% \mathrm{RH}$ and more slowly at $80 \% \mathrm{RH}$. Conidia held at $12^{\circ} \mathrm{C}$ were less affected by $\mathrm{RH}$, and maximum viability of conidia was 7 days at 40 and $80 \%$ RH and 10 days at $90 \% \mathrm{RH}$. Conidia held at $100 \%$ RH had significantly longer survival than those at lower humidities $(P<0.0001)$. At $100 \% \mathrm{RH}$, beginning at 21 days

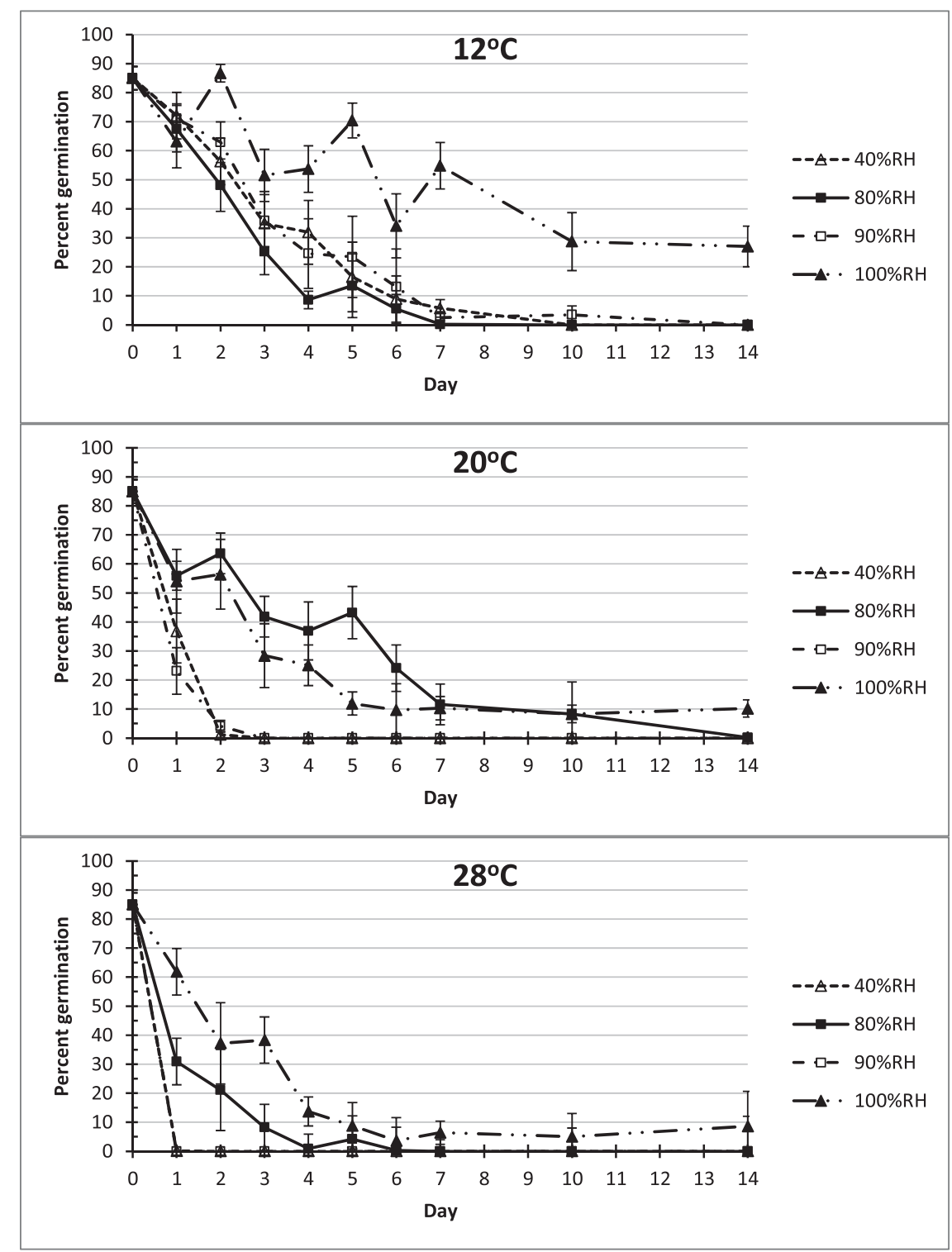

Fig. 3. Germination of dried Ophiognomonia clavigignenti-juglandacearum conidia held on nylon membranes at 12,20 , and $28^{\circ} \mathrm{C}$ and $40,80,90$, and $100 \%$ relative humidity $(\mathrm{RH})$ over 14 days. Conidia were germinated on water agar at $20^{\circ} \mathrm{C}$. Percentages are means of two isolates and three experiments $(n=6)$. Bars represent standard errors. 
for 20 and $28^{\circ} \mathrm{C}$ and 28 days for $12^{\circ} \mathrm{C}$, conidia started germinating on the membranes before they were plated (Table 3 ).

Viability of conidia after storage in water at various temperatures. Conidia did not germinate while in the water but started germinating when surface dried on the water agar. Conidial germination decreased steadily over time when held in water at all temperatures, from an initial mean of 91 to 43 and $26 \%$ at 14 and 28 days, respectively. Differences in germination between temperatures were slight at first but increased with time (Fig. 4). However, some conidia were viable with each temperature treatment for 168 days (the limit of the study).

\section{Discussion}

The evidence obtained in this study clearly indicates that O. clavigignenti-juglandacearum conidia are viable for extended periods and may have the ability for long-distance dispersal on various substrates.

Conidia of $O$. clavigignenti-juglandacearum germinated at a wide range of temperatures. Although rates of germination varied, $80 \%$ or greater of the conidia germinated in 8 days or less at temperatures of 8 to $28^{\circ} \mathrm{C}$. This agrees with the results of an earlier study (26), which showed germination at a similar range of temperatures. However, in that study, germination was monitored for only $48 \mathrm{~h}$ whereas, in this study, conidial germination was monitored 8 days or more at the lowest temperature. In the earlier study, conidial germination was not detected at $4{ }^{\circ} \mathrm{C}$ whereas, in this study, $80 \%$ of the conidia germinated at $4^{\circ} \mathrm{C}$ when held for a long enough period. Germination of conidia was somewhat inhibited at $32^{\circ} \mathrm{C}$ and completely inhibited at $36^{\circ} \mathrm{C}$, though it was not lethal if exposure was less than 4 days. When conidia were incubated at $20^{\circ} \mathrm{C}$ after an exposure to $36^{\circ} \mathrm{C}$ for 1 to 3 days, germination occurred.

The key factor for long-distance dispersal of infective conidia is the survival of dried conidia on a surface, such as the exoskeleton of an insect or body parts of a mammal or bird. The results of this study demonstrated that conidial viability can be sustained for about 16 days at nonsaturated humidity and for much longer periods in saturated humidity. These findings may have implications not just for the animal or insect potential vector of the fungus but also in movement of the fungus on scion wood, seed, and seedlings into areas where it is not presently found.

Researchers who have studied the survival of dried conidia have found that each species is unique. Conidia of Isaria fumosorosea had reduced viability under high temperatures and high humidity, with temperature being the key factor (1). Survival of Monilinia fructigena was negatively affected by high temperatures and low humidity, with temperature again being most important (27). In contrast, conidia of Gloeosporium musarum survived up to 70 days under most temperature and humidity combinations tested (7). In this present study, viability of conidia of $O$. clavigignenti-juglandacearum was affected by both temperature and humidity.

Clerk and Madelin (4) generally found a decrease in viability of stored conidia of B. bassiana, Paecilomyces farinosus, and Metarrhizium ansiopliae as humidity increased but did not test their conidia at saturated humidity. They also found that one fungus, M. ansiopliae,

Table 3. Longevity in days of air-dried Ophiognomonia clavigignenti-juglandacearum conidia in humidity chambers ${ }^{\mathrm{x}}$

\begin{tabular}{|c|c|c|c|c|c|c|c|}
\hline \multirow[b]{3}{*}{ Storage conditions } & \multicolumn{7}{|c|}{ Temperature $\left({ }^{\circ} \mathrm{C}\right)$} \\
\hline & \multicolumn{2}{|c|}{12} & \multicolumn{2}{|c|}{20} & \multicolumn{2}{|c|}{28} & \multirow{2}{*}{$\frac{\text { All combined }}{\text { Mean }^{y}}$} \\
\hline & Mean & Range & Mean & Range & Mean & Range & \\
\hline $40 \% \mathrm{RH}$ & 7 & 7 & 1 & $1-2$ & 0 & $0-1$ & $3 \mathrm{c}$ \\
\hline $80 \% \mathrm{RH}$ & 5 & $3-7$ & 15 & $10-21$ & 4 & $2-6$ & $8 \mathrm{~b}$ \\
\hline $90 \% \mathrm{RH}$ & 6 & $3-10$ & 2 & $1-2$ & 0 & 0 & $3 c$ \\
\hline $100 \% \mathrm{RH}^{\mathrm{z}}$ & 33 & $28-35$ & 24 & $21-28$ & 22 & $21-23$ & $26 \mathrm{a}$ \\
\hline Humidity combined ${ }^{y}$ & $13 \mathrm{~A}$ & $\ldots$ & $11 \mathrm{~B}$ & $\ldots$ & $7 \mathrm{~B}$ & $\ldots$ & $\ldots$ \\
\hline
\end{tabular}

${ }^{\mathrm{x}}$ Numbers represent the last day viable conidia were found, a mean of two isolates and three experiments $(n=6)$. Isolate $(P=0.92)$ and experiment $(P=0.94)$ differences were not statistically significant.

y Values with the same letter do not differ significantly according to Tukey's least significant difference test $(P<0.05)$.

${ }^{\mathrm{z}}$ After the day indicated, conidia frequently germinated on the membranes.

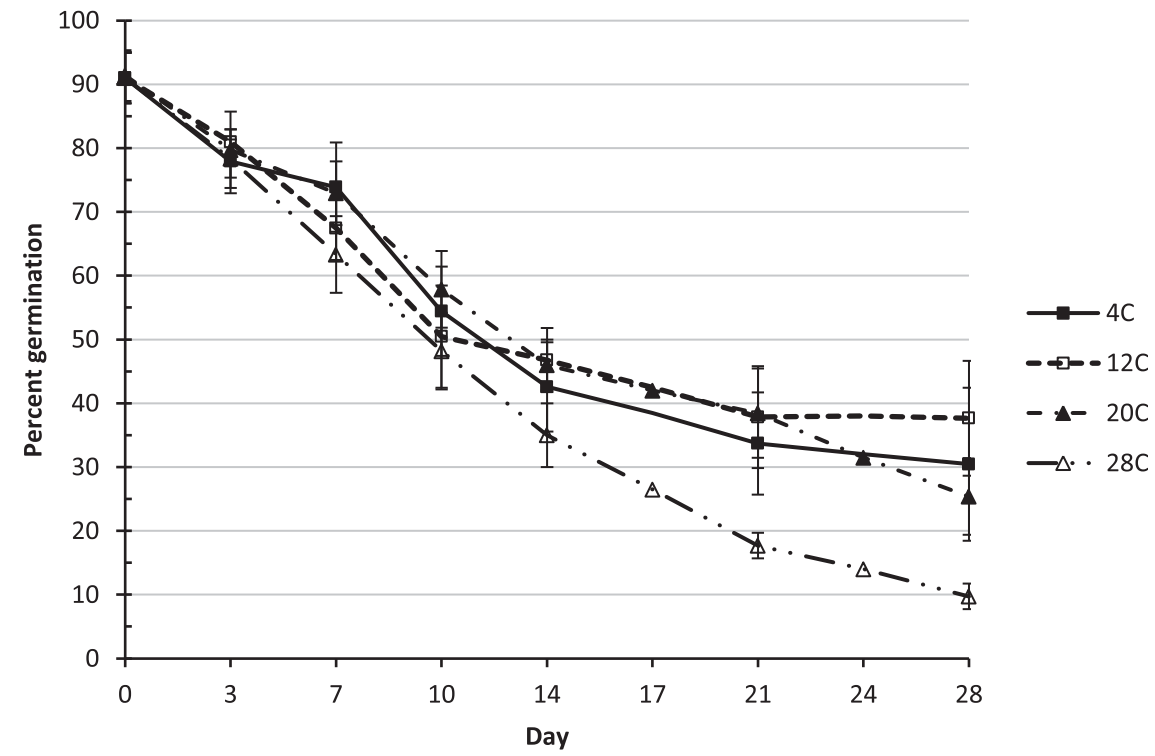

Fig. 4. Germination of Ophiognomonia clavigignenti-juglandacearum conidia after storage in water suspension at four temperatures. Conidia were germinated on water agar plates at $20^{\circ} \mathrm{C}$. Percentages are a mean of two isolates and three experiments $(n=6)$. Bars represent standard errors. 
had a longer period of viability at high and low humidities but a very short period of viability at 40 to $50 \% \mathrm{RH}$, demonstrating a unique viability curve. In comparison, $O$. clavigignenti-juglandacearum conidia demonstrated relatively poor viability at 40 and $90 \% \mathrm{RH}$ and better viability at $80 \% \mathrm{RH}$, also suggesting a unique conidia viability pattern.

This study also demonstrated that $O$. clavigignenti-juglandacearum conidia may remain viable for extended periods of time (over 24 weeks) in free water over a wide range of temperatures. This may have implications for dispersal in water runoff or streams, possibly infecting buttress roots of butternut trees.

O. clavigignenti-juglandacearum conidia are exuded in a sticky matrix from pycnidia and, in this study, the matrix was diluted in order to produce a suspension of conidia of known concentration. Preliminary studies found very poor germination of conidia in suspensions of high concentrations (unpublished data), possibly because of inhibitors present in the matrix. It has been reported that the matrix includes substances, usually polysaccharides and protein (12), which may increase longevity of conidia. Colletotrichum graminicola conidia survived up to 4 weeks when they remained embedded in the original matrix, versus washed conidia, which survived 1 to 2 days. Further studies involving the role of the matrix in conidial viability of O. clavigignenti-juglandacearum and other factors that may influence the viability of conidia such as the effect of UV light, the presence of other microbes, and surface chemistry should be investigated.

\section{Acknowledgments}

We thank J. S. Stanovick for his helpful statistical support.

\section{Literature Cited}

1. Bouamama, N., Vidal, C., and Fargues, J. 2010. Effects of fluctuating moisture and temperature regimes on the persistence of quiescent conidia of Isaria fumosorosea. J. Invertebr. Pathol. 105:139-144.

2. Broders, K. D., and Boland, G. J. 2011. Reclassification of the butternut canker fungus, Sirococcus clavigignenti-juglandacearum, into the genus Ophiognomonia. Fungal Biol. 115:70-79.

3. Broders, K. D., Boraks, A., Sanchez, A. M., and Boland, G. J. 2012. Population structure of the butternut canker fungus, Ophiognomonia clavigignentijuglandacearum in North American forests. Ecol. Evol. 2:2114-2127.

4. Clerk, G. C., and Madelin, M. F. 1965. The longevity of conidia of three insect-parasitizing hyphomycetes. Trans. Br. Mycol. Soc. 48:193-209.

5. Ficker, C. E., Arnason, J. T., Vindas, P. S., Alvarez, L. P., Akpagena, K., Gbeassor, M., De Souza, C., and Smith, M. L. 2003. Inhibition of human pathogenic fungi by ethnobotanically selected plant extracts. Mycoses 46:29-37.

6. Forney, C. F., and Brandl, D. G. 1992. Control of humidity in small controlledenvironment chambers using glycerol-water solutions. HortTechnology 2:52-54.

7. Goos, R. D., and Tschirsch, M. 1962. Effect of environmental factors on spore germination, spore survival, and growth of Gloeosporium musarum. Mycologia 54:353-367.

8. Halik, S., and Bergdahl, D. R. 2002. Potential beetle vectors of Sirococcus clavigignenti-juglandacearum on butternut. Plant Dis. 86:521-527.
9. Innes, L. 1997. Sirococcus clavigignenti-juglandacearum on butternut and black walnut fruit. Pages 129-132 in: Foliage, Shoot and Stem Diseases of Trees: Proc. IUFRO WP 70202 Meeting. G. Laflamme, J. A. Bérubé, and R. C. Hamelin, eds. Natural Resources Canada, Canadian Forest Service, Laurentian Forestry Centre, Québec City, Québec, Canada.

10. Katovich, S. A., and Ostry, M. E. 1998. Insects associated with butternut and butternut canker in Minnesota and Wisconsin. Great Lakes Entomol. 31: 97-108.

11. Nicholls, T. H. 1979. Butternut canker. Pages 73-82 in: Walnut Insects and Diseases: Workshop Proc. Carbondale, IL. Gen. Tech. Rep. NC-52. U.S. Dep. Agric. For. Serv. North Central For. Exp. Stn. St. Paul, MN.

12. Nicholson, R. L., and Moraes, W. B. C. 1980. Survival of Colletotrichum graminincola: Importance of the spore matrix. Phytopathology 70: 255-261.

13. Omar, S., Lemonier, B., Jones, N., Ficker, C., Smith, M. L., Neema, C., Towers, G. H. N., Goel, K., and Arnason, J. T. 2000. Antimicrobial activity of extracts of eastern North American hardwood trees and relation to traditional medicine. J. Ethnopharmacol. 73:161-170.

14. Orchard, L. P., Kuntz, J. E., and Kessler, K. J., Jr. 1982. Reactions of Juglans species to butternut canker and implications for disease resistance. Pages $27-$ 31 in: Black Walnut for the Future. Gen Tech. Rep NC-74. U.S. Dep. Agric. For. Serv. North Central For. Exp. Stn. St. Paul, MN

15. Ostry, M. E. 1997. Sirococcus clavigignenti-juglandacearum on heartnut (Juglans ailantifolia var. cordiformis). Plant Dis. 81:1461.

16. Ostry, M. E., Katovich, S., and Anderson, R. L. 1997. First report of Sirococcus clavigignenti-juglandacearum on black walnut. Plant Dis. 81: 830.

17. Ostry, M. E., and Moore, M. 2007. Natural and experimental host range of Sirococcus clavigignenti-juglandacearum. Plant Dis. 91:581-584.

18. Ostry, M. E., and Pijut, P. M. 2000. Butternut: An underused resource in North America. HortTechnology 10:302-306.

19. Ostry, M. E., and Woeste, K. 2004. Spread of butternut canker in North America, host range, evidence of resistance within butternut populations and conservation genetics. Pages 114-120 in: Black Walnut for a New Century, Proc. 6th Walnut Council Res. Symp. C. H. Michler, P. M. Pujut, J. V. Sambeek, M. Coggeshall, J. Seifert, K. Woeste, and R. Overton, eds. Gen. Tech. Rep. NC-243. U.S. Dep. of Agric. For. Serv. North Central Res. Stn. St. Paul, MN.

20. Renlund, D. W., ed. 1971. Pages 26-28 in: Forest Pest Conditions in Wisconsin, Annual Report 1971. Wisconsin Department of Natural Resources, Madison.

21. Stewart, J. E., Halik, S., and Bergdahl, D. R. 2004. Viability of Sirococcus clavigignenti-juglandacearum conidia on exoskeletons of three Coleopteran species. Plant Dis. 88:1085-1091.

22. Sun, X., Guo, L.-D., and Hyde, K. D. 2011. Community composition of endophytic fungi in Acer truncatum and their role in decomposition. Fungal Divers. 47:85-95.

23. Tisserat, N., and Kuntz, J. E. 1983. Dispersal gradients of conidia of the butternut canker fungus in a forest during rain. Can. J. Res. 13:1139-1144.

24. Tisserat, N., and Kuntz, J. E. 1983. Longevity of conidia of Sirococcus clavigignenti-juglandacearum in a simulated airborne state. Phytopathology $73: 1628-1631$.

25. Tisserat, N., and Kuntz, J. E. 1984. Butternut canker: Development on individual trees and increase within a plantation. Plant Dis. 68:613-616.

26. Tisserat, N. A. 1982. Epidemiology of butternut canker. Ph.D. dissertation, University of Wisconsin, Madison.

27. Xu, X. M., Guerin, L., and Robinson, J. 2001. Effects of temperature and relative humidity on conidial germination and viability, colonization and sporulation of Monilinia fructigena. Plant Pathol. 50:561-568. 